\title{
Implementasi Total Quality Managemen di SMPIT Abu Bakar Yogyakarta dan Implikasinya Terhadap Prestasi Sekolah
}

\author{
Akhsanul Fuadi \\ Email: akhsanulfuadi@almaata.ac.id \\ Universitas Alma Ata \\ Jl. Brawijaya No. 99 Yogyakarta
}

\begin{abstract}
Abstrak
Penerapan Total Quality Management mutlak dilakukan untuk meningkatkan prestasi sekolah. Total Quality Management dilaksanakan oleh SMPIT Abu Bakar Yogyakarta sebagai strategi melejitkan prestasi yang progressive di SMPIT Abu Bakar Yogyakarta, di mana manajemen tersebut diterapkan pada setiap aktifitas yang ada untuk mewujudkan prestasi yang progressive dan tidak pernah berhenti di SMPIT Abu Bakar Yogyakarta. Hasil implementasi strategi total quality management di SMPIT Abu Bakar Yogyakarta terbukti mampu meningkatkan prestasi dan kualitas pendidikan di SMPIT Abu Bakar Yogyakarta. Dari data yang ada mulai tahun pelajaran 2010/2011 SMPIT Abu Bakar meraih sebanyak lebih dari 200 kejuaraan yang diraih siswa dari tingkat kabupaten/kota sampai tingkat nasional bahkan ada satu event internasional (ASEAN), ada 10 kejuaraan yang diraih guru dari tingkat kabupaten/kota sampai ke tingkat Nasional, dan untuk kelembagaan, sekolah memperoleh penghargaan sebagai sekolah berintegritas tingkat nasional, sekolah model pendidikan keluarga tingkat nasional, sekolah model unggulan mutu tingkat propinsi, juara 1 sekolah berwawasan lingkungan untuk program asrama/pesantrennya.
\end{abstract}

Kata Kunci: Total Quality Manajemen, Prestasi Sekolah.

\begin{abstract}
Implementation of Total Quality Management is absolutely necessary to be implemented in school to increase school's achievement. Total Quality Management is implemented by SMPIT Abu Bakar Yogyakarta as a strategy to increase a progressive achievements at the SMPIT Abu Bakar Yogyakarta. This management is implemented to every aspect to realize the progressive achievements and never stop. The results of the implementation of the "Total Quality Management" strategy at SMPIT Abu Bakar Yogyakarta proved to be able to improve the achievements and quality of education at SMPIT Abu Bakar Yogyakarta. Based on the data starting from the 2010/2011 school year, Abu Bakar SMPIT won more than 200 championships by the students from the regency level to the national level. There was even one international event (ASEAN). There were 10 championships won by teachers from the regency level to the National level. For institutions, the school received an award as a school with national level integrity, a national family education model school, a superior quality model school at the provincial level, a champion of an environmentally friendly school for boarding program.
\end{abstract}

Keywords: Total Quality Management, School Achievement 


\section{PENDAHULUAN}

Tantangan sebuah lembaga pendidikan adalah bagaimana menjadikannya sebagai lembaga pendidikan yang berkualitas. Manajemen berkualitas sangat diperlukan untuk pengelolaan pendidikan yang maju, karena pendidikan merupakan fenomena fundamental atau asasi dalam kehidupan manusia, sehingga dapat dikatakan di mana ada kehidupan manusia, maka bagaimanapun juga di sana pasti ada pendidikan. ${ }^{1}$ Salah satu bentuk manajemen yang dapat diterapkan di sekolah adalah total quality managemen (TQM), di mana salah satu keberhasilan penerapan manajemen ini berada pada pimpinan tertinggi sekolah, yaitu kepala sekolah. Sebagai pemimpin di sekolah, kepala sekolah mempunyai peran yang besar dalam mengembangkan mutu pendidikan sekolah yang dipimpinnya. Kepimpinan kepala sekolah akan menentukan terwujud atau tidaknya visi dan misi sekolah sesuai dengan tujuan pendidikan. ${ }^{2}$ Menurut Undang-Undang Republik Indonesia nomor 20 tahun 2003 tentang Sistem Pendidikan Nasional (Sisdiknas) tujuan pendidikan adalah berkembangnya potensi peserta didik agar menjadi manusia yang beriman dan bertaqwa kepada Tuhan Yang Maha Esa, berakhlak mulia, sehat, berilmu, cakap, kreatif, mandiri, dan menjadi warga negara yang demokratis serta bertanggung jawab dalam bahasa lain tujuan pendidikan adalah untuk mewujudkan insan yang religius, berkarakter dan berketerampilan.

Tujuan pendidikan nasional tersebut juga menjadi tujuan dari SMPIT Abu Bakar Yogyakarta. Pada awal berdirinya, tahun 2001/2002, SMPIT Abu Bakar Yogyakarta merupakan salah satu sekolah yang dirancang untuk menjadi sekolah yang unggul baik dalam karakter/akhlak mulia dan ilmu pengetahuan serta diharapkan menjadi pilihan utama masyarakat di Daerah Istimewa Yogyakarta dan sekitarnya, bahkan di seluruh Indonesia. SMPIT Abu Bakar adalah bagian tidak terpisahkan dari sekolah Islam terpadu, dan masuk di bawah

${ }^{1}$ Maksudin, Pendidikan Nilai dan Karakter, (Yogyakarta: UIN Sunan Kalijaga Press, 2010), hlm 1.

${ }^{2}$ Sutomo, Manajemen Mutu Terpadu Berbasis Kearifan lokal, (Salatiga: Makalah, 2015), hlm. 1 naungan dinas pendidikan kota Yogyakarta atau mengikuti tata aturan yang diterapkan oleh kementerian pendidikan dan kebudayaan, yang selain melaksanakan sistem pendidikan nasional, ia juga mengusung keterpaduan antara ayat-ayat qauliyah dan ayat-ayat kauniyah. SMPIT adalah sekolah yang relatif baru, baru berusia 18 tahun, karena SMPIT Abu Bakar berdiri tahun 20012002 dan hanya mempunyai siswa sejumlah 19 siswa dengan dengan kualitas input yang "apa adanya". Dengan modal siswa yang hanya 19 siswa dan apa adanya, tentunya menjadi tantangan berat bagi SMPIT Abu Bakar yang mempunyai cita-cita ideal dan tidak menginginkan keberadaan sekolahnya menjadi masalah dan beban baru bagi dunia pendidikan/pemerintah, bahkan sebaliknya ingin memajukan pendidikan di Indonesia dengan ciri khasnya sebagai sekolah Islam terpadu. ${ }^{3}$

Namun, pada kenyataannya SMPIT Abu Bakar mampu menjawab tantangan berat tersebut dan menjadikan diri sebagai sekolah unggulan yang banyak diminati oleh masyarakat luas. Di antara keunggulan yang dicita-citakan banyak yang terwujud secara maksimal, seperti: (1) prestasi akademik dan non akademik banyak diraih, (2) kepercayaan masyarakat yang tinggi, dengan bukti animo pendaftar yang begitu "membludak" dan (3) budaya mutu sekolah yaitu "anak shalih dan berprestasi" sesuai mottonya sebagai pengejawantahan visi "melahirkan generasi muslim yang berpiribadi qur'ani, unggul dalam ilmu pengetahuan" benar-benar direalisasikan.

Salah satu managemen sebagai kunci sukses di SMPIT Abu Bakar Yogyakarta adalah dengan menerapkan konsep managemen melalui strategi total quality management (manajemen mutu terpadu), yang diterapkan secara kreatif dan konstruktif. ${ }^{4}$ Oleh karena itu, tulisan ini akan menggambarkan bagaimana berbagai

${ }^{3}$ Wawancara dengan Ahmad Agus Shofwan, Kepala Sekolah SMPIT Abu Bakar Yogyakarta yang pertama, 15 Juni 2019 di Kantor Yayasan SMPIT Abu Bakar Yogyakarta.

${ }^{4}$ Wawancara dengan Herry Purwanto, Kepala Sekolah SMPIT Abu Bakar Yogyakarta, 15 Juni 2019 di Kantor SMPIT Abu Bakar Yogyakarta. 
upaya untuk mengembangkan sekolah tersebut yang dituangkan dalam tulisan yang berjudul "Implementasi Total Quality Management Di SMPIT Abu Bakar Yogyakarta dan Implikasinya Terhadap Prestasi Sekolah”.

\section{METODE PENELITIAN}

Penelitian ini adalah penelitian kualitatif yang mengarah pada pendeskripsian secara rinci dan mendalam mengenai potret kondisi dalam suatu konteks, tentang apa yang sebenarnya terjadi menurut apa adanya di lapangan studinya. ${ }^{5}$ Penelitian ini memiliki beberapa karakteristik yaitu; pertama, berlangsung dalam latar ilmiah, ${ }^{6}$ kedua, peneliti adalah instrumen atau alat pengumpul data yang utama; ketiga, analisis datanya dilakukan secara induktif. ${ }^{7}$ Menurut Yin, fokus penelitian lebih berusaha menjawab pertanyaan tentang "bagaimana". ${ }^{8}$ Secara filosofis, sesuai dengan karakter data, teknik pengumpulan dan analisisnya penelitian ini mengacu pada pendekatan kualitatifnaturalistik dan lebih menekankan kepada makna. ${ }^{9}$

Teknik pengumpulan data yang digunakan meliputi; (1) observasi terlibat, (2) wawancara mendalam, dan (3) dokumentasi. Untuk menjamin akurasi data yang diperoleh dan kesesuainnya dengan masalah penelitian maka dilakukan telaah; (1) keaslian dokumen, (2) kebenaran isi dokumen, dan (3) relevansi isi dokumen dengan permasalahan yang dikaji dalam penelitian.

Analisis data dibagi ke dalam dua tahap; (1) analysis in the field, dan (2) analysis after data collection. Hasil yang diperoleh pada tahap

\footnotetext{
${ }^{5}$ Sutopo, H. B. Metodologi Penelitian Kualitatif. (Surakarta: UNS Press, 2006), hlm. 137

${ }^{6}$ Nasution, S., Metode Penelitian Naturalistik Kualitatif. (Bandung: Tarsito, 1998), hlm. 9-12

${ }^{7}$ Moleong, Lexy J., Metodologi Penelitian Kualitatif, (Bandung: Remaja Rosdakarya, Cet. XXII, 1989), hlm. 3

${ }^{8}$ Robert K. Yin, Case Study Research, Design And Methods. Terj. M. Jaudzi Mudzakir, (Jakarta: PT Raja Grafindo Persada, 1996), hlm. 18

${ }^{9}$ Noeng Muhadjir, Metodologi Penelitian Kualitatif (ed. IV), (Yogyakarta: Andi Offset, 2012), hlm. 21-22
}

pertama berupa catatan lapangan (field note) atau field work. Hasil analisis pada tahap ini berupa kesimpulan sementara yang diperoleh dari hasil observasi, dan kajian dokumen dengan menggunakan model analisis induktif. Data (kesimpulan) yang diperoleh pada analisis tahap pertama selanjutnya dikembangkan pada analisis tahap kedua, yaitu analysis after data collection. Pada tahap ini semua data dianalisis secara induktif dengan menggunakan analisis kualitatif deskriptif, yaitu dengan menguraikan berbagai fenomena pengelolaan dan aktivitas sekolah secara verbal.

Dalam penelitian ini diperlukan subjek penelitian, yaitu orang atau apa saja yang menjadi subyek penelitian. ${ }^{10}$ Pemilihan subyek atau sumber data dilakukan dengan menggunakan teknik purposive sampling yakni pemilihan sumber data dilakukan dengan pertimbangan tertentu. ${ }^{11}$ Dalam penelitian ini diperlukan subjek penelitian yang dijadikan sebagai informan. Subjek dipilih dan difokuskan pada orang-orang yang kompeten dan paham terhadap data-data yang dicari dan diperlukan dalam penelitian ini. Informan dalam penelitian ini di antaranya adalah pendiri dan pelaksana SMPIT Abu Bakar Yogyakarta mulai dari pimpinan sekolah, guru, karyawan, siswa dan orang tua yang paling mengetahui bagaimana kegiatan di SMPIT Abu Bakar Yogyakarta.

\section{HASIL DAN PEMBAHASAN Total Quality Management}

Total Quality Management (TQM) atau manajemen mutu terpadu adalah suatu konsep manajemen yang telah dikembangkan sejak lima puluh tahun lalu dari berbagai praktek manajemen serta usaha peningkatan dan pengembangan produktivitas. ${ }^{12}$

\footnotetext{
${ }^{10}$ Suharsimi Arikunto, Prosedur Penelitian Suatu Pendekatan Praktis, (Jakarta: Rineka Cipta, 1998), hlm. 4.

${ }^{11}$ Sugiyono, Metode Penelitian Pendidikan, Pendekatan Kuantitatif, Kualitatif, dan R\&D, (Bandung: Alfabeta, Cet. IX, 2010), hlm. 300.

${ }^{12}$ Ahmad Ali Riyadi, Manajemen Mutu Pendidikan, (Yogyakarta: Irchisod, 2007), hlm. 5
} 
Di masa lampau, literatur manajemen berfokus pada fungsi-fungsi kontrol kelembagaan, termasuk perencanaan, pengorganisasian, perekrutan staf, pemberian arahan, penugasan, strukturisasi dan penyusunan anggaran. Konsep manajemen ini membuka jalan menuju paradigma berpikir baru yang memberi penekanan pada kepuasan pelanggan, inovasi dan peningkatan mutu pelayanan secara berkesinambungan. Faktor-faktor yang menyebabkan lahirnya "perubahan paradigma" adalah menajamnya persaingan, ketidakpuasan pelanggan terhadap mutu pelayanan dan produk, pemotongan anggaran serta krisis ekonomi. Meskipun akar TQM berasal dari model-model perusahaan dan industri, namun kini penggunaannya telah merambah sturuktur manajemen, baik di lembaga pemerintah maupun lembaga nirlaba. ${ }^{13}$

Alasan pemilihan total quality management (TQM) di SMPIT Abu Bakar ini dilandasi bahwa sistem manajemen ini terbukti sukses diterapkan di beberapa lembaga. Adapun penerapannya di SMPIT Abu Bakar berbasis kearifan lokal (pembinaan karakter dan penguatan ruhani) sebagai strategi melejitkan prestasi yang progressive di SMPIT Abu Bakar Yogyakarta. Hal ini dilandasi pemikiran bahwa melejitkan prestasi siswa, guru, maupun sekolah dapat terlaksana apabila (1) fokus terhadap pembinaan karakter dan penguatan ruhani, (2) agar sekolah melakukan inovasi secara konstan, melakukan perbaikan dan perubahan terarah dengan melakukan perbaikan secara terus menerus, serta mempunyai "pijakan" kuat dalam tata kelola pembinaan karakter untuk mencapai prestasi (3) melibatkan seluruh warga sekolah memiliki culture serta habit yang menghantarkan untuk meraih prestasi. ${ }^{14}$

Strategi yang dilaksanakan untuk memecahkan permasalahan di SMPIT Abu Bakar Yogyakarta adalah mengimplementasikan

\footnotetext{
${ }^{13}$ http: \\total-quality-management-tqm-ringkasan. html. diunduh 26 April 2019.

${ }^{14}$ Wawancara dengan Herry Purwanto, Kepala Sekolah SMPIT Abu Bakar Yogyakarta, 15 Juni 2019 di Kantor SMPIT Abu Bakar Yogyakarta
}

TQM terhadap peserta didik, guru, komite, karyawan, dan seluruh stake holder. Strategi total quality management berbasis keunggulan lokal (pembinaan karakter dan penguatan ruhani) di mana manajemen tersebut dilandaskan pada keunggulan lokal, yaitu pembinaan karakter siswa sebagai langkah penguatan ruhani untuk mewujudkan prestasi yang progressive di SMPIT Abu Bakar Yogyakarta. ${ }^{15}$

\section{Tahap Operasional/Langkah-langkah Total Quality Managemen}

Tahapan operasional/langkah-langkah pelaksanaan TQM di SMPIT Abu Bakar adalah sebagai berikut ini :

\section{Menjalin komunikasi yang baik}

Kerjasama yang baik telah dilakukan oleh SMPIT Abu Bakar di antaranya dengan pihak orangtua siswa selaku pendidik utama para siswa SMPIT Abu Bakar Yogyakarta, selain itu kerja sama dengan berbagai pihak baik dalam negeri atau luar negeri. Kerja sama dengan berbagai pihak dalam negeri bertujuan untuk meningkatkan pelayanan dan mutu sekolah. Kerja sama dengan berbagai pihak luar negeri bertujuan untuk lebih meningkatkan mutu sekolah untuk menjadi sekolah unggul atau efektif. Beberapa kerja sama yang dilaksanakan yaitu dengan sekolah swasta yang ada di Pattani Thailand.

\section{Pembiasaan yang baik}

Kegiatan pembiasaan siswa dilaksanakan rutin dan terprogram untuk membentuk sikap anak cerdas berakhlak mulia sebagai pengejawantahan dari visi melahirkan generasi qur'ani, unggul dalam ilmu pengetahuan dan penanaman karakter islami. Hal ini, dimaksudkan agar identitas dan karakter sebagai masyarakat Indonesia tetap dipertahankan dan sesuai budaya islami.

\footnotetext{
${ }^{15}$ Wawancara dengan Ibu Maria, Guru Senior dan Pernah Menjabat Sebagai Wakil Kepala Sekolah Bidang SDM, Selasa, 20 Juli 2019
} 


\section{Pembentukan pribadi yang berakhlak mulia}

Akhlak atau moral harus dibina sejak dini apalagi di usia SMP yang memasuki fase remaja sebagai bekal untuk menjadi insan yang bertanggung jawab dalam bersosialisasi dengan masyarakat dalam kehidupan seharihari. "Sejuta Pesan" (semangat, jujur, tanggung jawab, peduli dan santun) yang merupakan penerapan karakter siswa, dengan motto "Membimbing Sepenuh Hati Agar Shalih dan Berprestasi" ini dapat dilihat dari penerapan sikap dengan $5 \mathrm{~S}$ (senyum, salam, dan sapa, sopan, santun), prinsip saling menghormati, jujur, serta peduli terhadap orang lain sebagai perwujudan dari karakter semangat, jujur, tanggung jawab, peduli dan santun. ${ }^{16}$ Di antara kegiatan yang dilakukan untuk membentuk kebiasaan yang baik dan pembentukan akhlak mulia adalah dengan :

Shalat dhuha dan membaca al-Qur'an bersama dilanjutkan dengan doa. kegiatan ini rutin dan wajib dilaksanakan semua civitas akademika, terlebih para siswa setiap pagi dari pukulm 07.00-07.30 wib. Dalam kegiatan ini senantiasa dilakukan sholat dhuha, membaca al-Qur'an bersama dipimpin oleh siswa yang bertugas dan diakhiri dengan do'a.

Penanaman karakter "sejuta pesan": semangat, jujur, tanggung jawab, peduli dan santun melalui aktifitas harian, pekanan, dan bulanan.

Pesantren tahfidz setiap hari. Kegiatan ini diberlakukan setiap hari, kecuali hari Rabu. Istilah program ini dipergunakan untuk sebuah kegiatan menghafal al-Qur'an yang diperuntukkan bagi para siswa yang mempunyai kecenderungan menghafal dan mempunyai kemampuan lebih dalam bidang al-Qur'an sehingga mereka ditargetkan hafal minimal 7-10 juz al-Qur'an. Mabit dan tadabbur al-Qur'an. Kegiatan ini dilaksanakan setiap bulan, di mana pada hari

${ }^{16}$ Wawancara dengan Bapak Ma'ruf, Guru SMPIT Abu Bakar Yogyakarta, 15 Juni 2019 di Kantor SMPIT Abu Bakar Yogyakarta yang dijadwalkan setiap siswa diwajibkan mabit (menginap) pada tempat-tempat yang ditunjuk (biasanya masjid-masjid di wilayah DIY) untuk berinteraksi dengan al-Qur'an/ membaca dan menghafal seharian penuh, serta kajian tafsir al-Qur'an.

Oase, AMT, ESQ. kegiatan ini dilaksanakan setiap bulan untuk mencerahkan dan menguatkan hati serta memberikan motivasi pada semua siswa. Selanjutnya adalah kegiatan Pekan pembinaan ruhani: adalah sebuah program yang rutin dilakukan sebagai pantauan atas kegiatan peribadahan siswa demi kuatnya ruhani untuk melejitkan prestasi

Program we care we share, adalah bentuk kegiatan sosial yang terprogram, dimana setiap siswa diharuskan mampu memberikan yang terbaik untuk orang banyak dan lingkungan sekitar, sehingga keberadaan mereka memberikan manfaat untuk umat dan lingkungan. Program-program tersebut dikuatkan lagi untuk menginternalisasikan minimal lima karakter awal yang senantiasa harus dimiliki oleh siswa yaitu semangat, jujur, tanggung jawab, peduli dan santun yang disingkat menjadi sejuta pesan.

\section{Pengkodisian ekosistem sekolah yang baik dan terbuka}

Pengkodisian ekosistem sekolah yang baik dan terbuka adalah program sekolah yang dilaksanakan oleh seluruh warga sekolah untuk melakukan forum komunikasi antara sekolah dan orang tua (POMG) baik dengan seluruh orang tua siswa bersama-sama ataupun dalam forum diskusi. Diskusi dilakukan oleh kepala sekolah dengan kelompok kerja (guru, karyawan, dan komite). Hasil dari diskusi tersebut dapat diterapkan dalam proses peningkatan mutu dan prestasi sekolah secara berkelanjutan.

\section{Pembimbingan/Pembinaan dan pelatihan untuk guru}

Pembimbingan dan pelatihan guru diadakan untuk meningkatkan kualitas guru. Beberapa pembimbingan yang rutin 
dilaksanakan di sekolah yaitu IHT (In House Training), pembinaan untuk peningkatan kualitas guru seperti pelatihan TIK (Teknologi Informasi dan Komunikasi), pembuatan kisikisi dan soal, silabus, RPP, dan pelatihan pembuatan media pembelajaran serta fasilitasi guru yang mau mengikuti kegiatan aktualisasi diri/lomba. Selain pelatihan tersebut, juga ada pembinaan pekanan untuk semua guru dan karyawan dalam rangka mencapai kekuatan ruhiyah agar mampu menjadi pendidik yang memberikan pembimbingan optimal untu semua peserta didik.

\section{Optimalisasi pengembangan diri bagi siswa}

Kegiatan pengembangan diri bagi siswa bertujuan untukmemfasilitasi dan mengembangkan bakat siswa. Kegiatan pengembangan diri dimasukkan dalam kegiatan ekstrakurikuler. Selain itu ada program pengembangan bakat minat dengan layanan intensif atau khusus.

\section{Hasil Penerapan Total Quality Managemen} Hasil penerapan total quality managemen di SMPIT Abu Bakar dapat dideskripsikan sebagai berikut:

\section{Terbangunnya komunikasi yang baik dengan berbagai pihak}

SMPIT Abu Bakar merupakan salah satu sekolah swasta Islam yang berada di Daerah Istimewa Yogyakarta yang memiliki pluralisme atau keragaman baik suku, kebiasaan maupun adat-istiadat, karena siswa yang menuntut ilmu di dalamnya berasal dari berbagai wilayah di Indonesia. SMPIT Abu Bakar membangun pendidikan multikultural dengan memperhatikan kondisi pluralisme tersebut. Berikut penjabaran komunikasi dan kerja sama yang dilakukan SMPIT Abu Bakar Yogyakarta dengan berbagai pihak:

\section{Komunikasi efektif dan kerjasama dengan para orang tua}

SMPIT Abu Bakar mulai tahun 2015/2016 ditunjuk sebagai sekolah model pendidikan berbasis keluarga oleh kementerian pendidikan dan kebudayaan. Hal ini ini tidak terlepas dengan adanya komunikasi dan kerja sama yang baik antara sekolah dengan para orang tua yang merupakan pendidik utama bagi para siswa. Di antara kegiatan yang rutin dilakukan adalah adanya forum POMG (pertemuan orang tua murid dan guru) sebagai strategi menyamakan persepsi pendidikan di sekolah dan di rumah. Kegiatan ini rutin dilaksanakan setiap bulan dengan mengundang para nara sumber yang ahli dalam bidangnya dengan topik bahasan yang berbeda sesuai kebutuhan. Para nara sumber ini juga melibatkan para orang tua yang ahli dalam bidang keilmuan yang dibutuhkan.

\section{Komunikasi dan kerja sama dalam negeri serta luar negeri}

Komunikasi dan kerja sama yang telah terjalin untuk memajukan kualitas pendidikan di SMPIT Abu Bakar Yogyakarta antara lain kerja sama selain dengan sekolah-sekolah yang berada dalam jaringan sekolah islam terpadu, juga menjalin kerjasama dengan sekolahsekolah yang lain, baik dalam jenjang yang sama (SMP) maupun dengan jenjang yang lebih rendah atau lebih tinggi (TK, SD, SMA). Kerja sama dengan jenjang SMP sebagai bentuk study banding, kerja sama dengan TK, SD sebagai bentuk aplikatif keilmuan para siswa, dan kerjasama dengan SMA maupun lembaga yang secara jenjang di atanya sebagai bentuk tindak lanjut study siswa. Komunikasi dan kerja sama juga dilakukan dengan lembaga-lembaga negeri, swasta, dan masyarakat yang ada di sekitar Daerah Istimewa Yogyakarta.

Komunikasi dan kerja sama dengan pihak luar negeri dikembangkan oleh SMPIT Abu Bakar Yogyakarta seperti Pattani, Thailand. Kerja sama dilaksanakan dalam bidang manajemen sekolah, pengembangan mutu sekolah, habbit, culture, dan dalam rangka peningkatan prestasi siswa.

\section{Terlaksananya kegiatan pembiasaan Yang Berkualitas}

Kegiatan pembiasaan yang dilakukan di SMPIT Abu Bakar Yogyakarta diharapkan 
dapat membentuk karakter. Pembiasaan yang diterapkan adalah membiasakan beribadah, menjaga kebersihan, cinta tanah air, dan semangat menghafal al-Qur'an dan mengamalkannya. Kegiatan pembiasaan ada 4, yaitu:

Pembiasaan rutin meliputi: 1) mengucap salam dan berjabat tangan, 2) shalat dhuha setiap pagi, 3) tilawah/ tadarus al-Quran setelah shalat dhuha dan dilanjutkan dengan doa, 4) shalat berjamaah dzuhur, ashar untuk siswa prorgam fullday dan shalat jamaah lima waktu untuk siswa asrama/pesantren dilanjutkan dengan dzikir ba'da shalat 5) upacara bendera, 6) kebersamaan dalam makan yang diawali berdoa sebelum dan sesudah makan.

Pembiasaan terprogram meliputi: 1) pesantren tahfidz setiap hari, dalam rangka agar siswa yang mempunyai kecenderungan menghafal al-Qur'an mampu menguasai hafalan 7-10 juz al-Qur'an, 2) pesantren ramadhan, 3) bakti sosial dan pelaksanaan idul qurban, 4) kegiatan sosial dan dakwah, dan 5) We care We Share, 6). Oase, AMT, 7) MABIT (Malam Bina Iman dan Takwa) 8) Pekan pembinaan ruhani

Kegiatan nasionalisme dan patriotisme. Kegiatan ini memiliki tujuan untuk menumbuhkan rasa cinta tanah air dan mempraktikkan sikap nasionalisme dan patriotisme dalam kehidupan sehari-hari. Beberapa peringatan yang dilaksanakan yaitu peringatan hari Kemerdekaan RI, hari Pahlawan, hari Kartini, hari Pendidikan Nasional, SUmpah Pemuda dan peringatan hari besar lainnya sebagai wujud kecintaan terhadap bangsa dan Negara Indonesia.

Kegiatan cinta lingkungan. Ada satu hari, yang dinamakan dengan "yaumun nasyath", di mana pada hari tersebut para siswa melaksanakan bakti lingkungan. Kegiatan ini bertujuan agar siswa memiliki kesadaran menjaga kebersihan dan melestarikan lingkungan agar tercipta lingkungan sehat sehingga mendukung aktivitas belajar mengajar dengan suasana yang nyaman.

\section{Terbentuknya pribadi yang berakhlak mulia}

Pembentukan akhlak mulia di SMPIT Abu Bakar Yogyakarta bertujuan untuk membentuk karakter yang dapat diterapkan dalam berkomunikasi dan bersosialisasi di lingkungan masyarakat. Proses pembentukan karakter sejuta pesan ini secara tidak langsung mengajarkan unggah-ungguh yang berbasis keunggulan lokal dan agama dalam berinteraksi dengan orang lain dan peka terhadap keadaan sekitar.

\section{Terbangunnya ekosistem sekolah yang terbuka}

Iklim keterbukaan di SMPIT Abu Bakar Yogyakarta ditunjukkan dari beberapa pertemuan intensif dengan guru, wali murid, komite, dan yayasan. Hal ini dilakukan agar warga sekolah mengedepankan keterbukaan, menghargai pendapat orang lain, dan membiasakan musyawarah. Proses ini secara tidak langsung melestarikan keunggulan lokal, yaitu musyawarah untuk mencapai mufakat dan budaya prestasi. Atas dasar inilah, kemudian menjadikan SMPIT Abu Bakar Yogyakarta, dipilih menjadi sekolah percontohan pendidikan berbasis keluarga. Dan karena iklim keterbukaan ini, sangat mudah bagi SMPIT Abu Bakar untuk menerapkan tata kelola aturan terkait standar karakter dan kelulusan, diantaranya dengan menerapkan konsep Ijazah Islam Terpadu dalam segi penilaian karakter dan pembiasaan ibadah siswa untuk mencapai kekuatan ruhani dalam melejitkan prestasi tiada henti di SMPIT Abu Bakar Yogyakarta.

Penerapan pembinaan karakter dan penguatan ruhani terbukti dapat meningkatkan prestasi sekolah. Tabel 1 yang menjelaskan data prestasi sekolah yang telah dicapai. ${ }^{17}$

\section{Terlaksananya pembimbingan dan pelatihan untuk Guru (training)}

Pelatihan rutin untuk guru di SMPIT Abu Bakar Yogyakarta ada dua macam, yaitu pelatihan rutin untuk mencapai kompetensi pedagogis dan profesional dan pelatihan

${ }^{17}$ Dokumentasi SMPIT Abu Bakar, Tahun 2013 
Tabel 1. Prestasi sekolah/Kelembagaan mulai tahun ajaran 2012/2013

\begin{tabular}{lcc}
\hline $\begin{array}{c}\text { Penghargaan/sertifikasi yang } \\
\text { diperoleh }\end{array}$ & Tahun & $\begin{array}{c}\text { Instansi } \\
\text { pemberi }\end{array}$ \\
\hline $\begin{array}{l}\text { Sekolah Model Unggulan Mutu } \\
\text { Pendidikan } \\
\text { Sekolah Model Pendidikan }\end{array}$ & 2016 & Dikpora DIY \\
$\begin{array}{l}\text { Berbasis Keluarga Tingkat } \\
\text { Nasional }\end{array}$ & 2016 & Kemendikbud \\
$\begin{array}{l}\text { Sekolah Berintegritas Tingkat } \\
\text { Nasional }\end{array}$ & 2015 & Kemendikbud \\
$\begin{array}{l}\text { Pesantren Berwawasan } \\
\text { Lingkungan Hidup (Program }\end{array}$ & 2015 & Kemenag Kota \\
$\begin{array}{l}\text { Boarding Sekolah) } \\
\text { Sekolah Pelaksana/Sasaran }\end{array}$ & 2013 & Kemendikbud \\
Kurikulum 2013 & & \\
\hline
\end{tabular}

rutin yang sifatnya ruhiyah untuk mencapai kompetensi kepribadian dan sosial. Pelatihan rutin untuk mencapai kompetensi pedagogis dan profesiona di antaranya dengan pembuatan media pembelajaran, pelatihan bimbingan konseling, pelatihan pembuatan kisi-kisi, soal, silabus, pelatihan TIK, IHT pembinaan dan pelatihan rutin di SMPIT Abu Bakar Yogyakarta setiap awal tahun pelajaran baru dan pelatihanpelatihan lain yang menunjang ketercapaian mutu sekolah. Sementara, pelatihan rutin yang sifatnya ruhiyah dilaksanakan setiap pekan dengan guru senior yang ditunjuk.

Penerapan kegiatan training tersistem dan pembinaan pekanan rutin untuk guru dan tenaga kependidikan dilakukan agar selalu belajar, berusaha memperbaiki kekurangan, dan memberikan prestasi yang terbaik untuk sekolah. Penerapan tersebut terbukti dapat meningkatkan prestasi kepala sekolah dan guru, dan setidaknya ada beberapa guru yang berprestasi dalam bidang-bidang yang berbedabeda, di antaranya: Acep Yonny sebagai juara sayembara penulisan naskah buku pengayaan tingkat nasional, Suwi Wahyu utami, Guru BK yang berprestasi dalam kegiatan PTK se-Jawa, Maharsi dan Maria yang berprestasi dalam bidang Olimpiade Sains Naional (OSN). ${ }^{18}$

${ }^{18}$ Wawancara dengan Ibu Eko, Wakil Kepala Sekolah Bidang Kurikulum, Selasa, 20 Juli 2019

\section{Terlaksananya Kegiatan Pengembangan Diri Bagi Siswa}

Pengembangan diri dilakukan melalui ekstrakurikuler yang ada di SMPIT Abu Bakar Yogyakarta juga memperhatikan keunggulan lokal antara lain:

Kegiatan ekstrakurikuler atau pengembangan diri

Ada 14 kegiatan ekstrakurikuler dan komunitas minat dan bakat di SMPIT Abu Bakar, diantaranya yaitu: pramuka SIT, Beladiri Karate, Elektronika/robotika, Jurnalistik, KIR, ESC, Sport Club, tari tradisional, khitobah, klub bahasa, pleton inti, nasyid, hadrah dan lain-lain.

\section{Kegiatan field study dan outdoor learning}

Beberapa kegiatan field study dan outing class atau kunjungan belajar telah dilaksanakan dalam pembelajaran di SMPIT Abu Bakar di antaranya kunjungan belajar (field study) ke Taman Pintar, pabrik keramik dan gerabah, museum-museum dan lain-lain. Selain itu kegiatan ini disesuaikan dengan tema pelajaran dan pembentukan karakter mulia. Penerapan aktifitas siswa dengan meningkatkan kegiatan ekstrakulikuler, field study, dan outdoor learning kepada para siswa terbukti dapat meningkatkan prestasi siswa. Berikut tabel 2 peningkatan hasil prestasi siswa yang telah dicapai.

Tabel 2. Prestasi Siswa dari Tahun Ajaran 2010/2011 tingkat Kota

\begin{tabular}{ll}
\hline Prestasi Siswa (Bidang) & Capaian Prestasi \\
\hline OSN dan Akademik & 93 Penghargaan Lomba/ \\
& Kejuaraan \\
Olahraga & 158 Penghargaan Lomba/ \\
& Kejuaraan \\
Keagamaan (MTQ dll) & 155 Penghargaan Lomba/ \\
& Kejuaraan \\
Ekstra kurikuler/Minat & 168 Penghargaan Lomba/ \\
Bakat yang lain & Kejuaraan \\
\hline
\end{tabular}

Dari sisi Ujian Nasional, berdasarkan data yang dikeluarkan oleh Dinas Pendidikan, Pemuda dan Olahraga tanggal 28 Mei 2019, sebagaimana dilansir oleh Tribun.com, SMPIT Abu Bakar menjadi sekolah terbaik swasta se-DIY dalam perolehan nilai Ujian nasional. 
Tabel 3. Jumlah input dan jumlah siswa dari tahun ajaran 2009/2010

\begin{tabular}{cccccccccc}
\hline \multirow{2}{*}{ Tahun Ajaran } & \multirow{2}{*}{$\begin{array}{c}\text { Jml Pendaftar } \\
\text { (Calon Siswa Baru) }\end{array}$} & \multicolumn{2}{c}{ Kelas VII } & \multicolumn{2}{c}{ Kelas VIII } & \multicolumn{2}{c}{ Kelas IX } & \multicolumn{2}{c}{ Jumlah Total } \\
\cline { 3 - 9 } & & Siswa & $\begin{array}{c}\text { Jumlah } \\
\text { Rombel }\end{array}$ & $\begin{array}{c}\text { Jml } \\
\text { Siswa }\end{array}$ & $\begin{array}{c}\text { Jumlah } \\
\text { Rombel }\end{array}$ & $\begin{array}{c}\text { Jml } \\
\text { Siswa }\end{array}$ & $\begin{array}{c}\text { Jumlah } \\
\text { Rombel }\end{array}$ & $\begin{array}{c}\text { Jml } \\
\text { Siswa }\end{array}$ & $\begin{array}{c}\text { Jumlah } \\
\text { Rombel }\end{array}$ \\
\hline $2009 / 2010$ & 180 & 145 & 4 & 129 & 4 & 84 & 3 & 358 & 11 \\
$2010 / 2011$ & 199 & 177 & 6 & 143 & 4 & 126 & 4 & 446 & 14 \\
$2011 / 2012$ & 363 & 242 & 8 & 171 & 6 & 138 & 4 & 551 & 18 \\
$2012 / 2013$ & 420 & 253 & 8 & 235 & 8 & 172 & 6 & 660 & 22 \\
$2013 / 2014$ & 513 & 289 & 8 & 255 & 8 & 235 & 8 & 779 & 24 \\
$2014 / 2015$ & 493 & 250 & 8 & 265 & 8 & 245 & 8 & 760 & 24 \\
$2015 / 2016$ & 498 & 256 & 8 & 251 & 8 & 265 & 8 & 772 & 24 \\
$2016 / 2017$ & 498 & 266 & 8 & 256 & 8 & 250 & 8 & 772 & 24 \\
$2017 / 2018$ & 515 & 266 & 8 & 260 & 8 & 255 & 8 & 781 & 26 \\
$2018 / 2019$ & 540 & 320 & 10 & 260 & 8 & 316 & 8 & 896 & 26 \\
$2019 / 2020$ & 590 & 320 & 10 & 320 & 10 & 318 & 8 & 958 & 28 \\
\hline
\end{tabular}

Adapun data lengkap 10 SMP Swasta terbaik di Provinsi DI Yogyakarta berdasarkan rerata nilai UN 2019 adalah sebagai berikut : 1. SMP Islam Terpadu Abu Bakar: total retata UN 86,84, 2. SMPTK Partriae Academy: total retata UN 85,26, 3. SMP Olifant: total retata UN 84,17, 4. SMP Kesatuan Bangsa: total retata UN 82,81, 5. SMP Pangudi Luhur: total retata UN 81,50, 6. SMP Cahaya Bangsa Utama: total retata UN 80,97, 7. MTS Taruna Al-Quran: total retata UN 80,46, 8. SMP Islam Terpadu Bina Anak Sholeh: total retata UN 80,05, 9. SMP Budi Utama Mlati: total retata UN 79,91, 10. SMP Stella Duce 1 Yogyakarta: total retata UN 79,81. ${ }^{19}$

\section{Dampak dari Strategi yang Dipilih}

Dampak dari penerapan TQM di SMPIT Abu Bakar Yogyakarta yaitu meningkatnya kualitas dan kuantitas input siswa. Kuantitas dan kualitas input siswa setiap tahun mengalami peningkatan karena adanya antusiasme dan kepercayaan dari masyarakat.

Berdasarkan data pada table 3, jumlah pendaftar calon siswa baru selalu mengalami peningkatan setiap tahunnya. Selain berdampak pada kuantitas input siswa, berdampak pula pada kualitas output siswa yang unggul. Hal ini

\footnotetext{
${ }^{19}$ Sumber berita jogja dari Dinas Pendidikan, Pemuda dan Olahraga, https://www.jogja.co/10-smpswasta-di-diy-ini-raih-rerata-nilai-unbk-tertinggi-2019/, 28 Mei 2019. Data tersebut juga dibuktikan dengan dokumen hasil UN SMPIT Abu Bakar Yogyakarta mulai tahun 2013-2019.
}

terbukti selain dengan naiknya nilai akademik (UN) siswa, dan menjadi finalis OSN tingkat Nasional dalam sejak tahun 2012-sekarang, dan meningkatnya prestasi akademik dan non akademik siswa serta dari diterimanya siswa lulusan SMPIT Abu Bakar Yogyakarta di sekolah-sekolah negeri maupun swasta terbaik di DIY dan berbagai wilayah di Indonesia. Selanjutnya, dampak yang dirasakan menjadi rujukkan studi banding bagi sekolah-sekolah di seluruh Indonesia.

\section{KESIMPULAN}

Setelah melakukan penelitian dan analisis data, dapat disimpulkan bahwa SMPIT Abu Bakar Yogyakarta yang pada awalnya merupakan sekolah yang hanya diisi oleh beberapa siswa, kemudian banyak memperoleh prestasi dan diminati masyarakat banyak disebabkan oleg beberapa hal, yaitu :

SMPIT Abu Bakar Yogyakarta benarbenar menerapkan konsep TQM secara baik dengan konsentrasi pada keunggulan lokal yang dimilikinya, yaitu pembinaan karakter sebagai strategi meningkatkan kualitas dan prestasi sekolah.

Total quality management sebagai strategi melejitkan prestasi yang progressive di SMPIT Abu Bakar Yogyakarta menjadi 6 tahap, yaitu (a) membangun komunikasi yang baik, (b) membentuk kebiasaan yang baik, (c) membentuk akhlak yang baik, (d) membangun ekosistem sekolah yang terbuka (e) 
pelaksanaan training dan pembinaan guru, dan (f) pelaksanaan kegiatan siswa dalam rangka membentuk karakter mulia dan penguatan ruhani.

Hasil implementasi TQM adalah (a) terbangunnya komunikasi yang baik pada semua pihak (b) terbentuknya pembiasaan peribadahan yang baik pada warga sekolah, (c) terbentuknya akhlak mulia/karakter (d) terlaksananya ekosistem sekolah yang terbuka, (e) terlaksanannya training dan pembinaan guru dan karyawan, dan (f) terlaksananya activitas siswa berupa pengembangan diri yang berkualitas.

Dampak implementasi TQM berbasis keunggulan lokal (pembinaan karakter dan penguatan ruhani) adalah meningkatnya: (a) kepercayaan masyarakat, (b) kuantitas dan kualitas input siswa, (c) kualitas output, dengan ketercapaian SKL dengan keseimbangan dalam prestasi akademik dan non akademik dan (d) dukungan stake holder.

\section{DAFTAR PUSTAKA}

Arikunto, Suharsimi. 2002. Prosedur Penelitian Suatu Pendekatan Praktik. Jakarta: PT. Rineka Citra.

Bungin, Burhan. 2003. Analisis Data Penelitian Kualitatif. Jakarta: PT. Raja Grafindo.

Depdiknas. 2000. Panduan Manajemen Sekolah. Jakarta: Departemen Pendidikan Nasional Direktorat Jendral Pendidikan Dasar dan Menengah Direktorat Pendidikan Menengah Umum.
Fajarini, Ulfah. 2014. Peranan Kearifan Lokal dalam Pendidikan Karakter. Jurnal Sosio Didaktika Vol. 1 No. 2 Des 2014

Joseph, C.F. 1993. Total Quality Management. Kuala Lumpur: S.Abdul Majeed \& Co.

Rahyono, F. X. 2009. Kearifan Budaya dalam Kata. Jakarta: Wedatama Widyasatra.

Sallis, E. Alih Bahasa Ali riyadi, Ahmad \& Fahrurozi. 2006. Total Quality Management in Education: Manajemen Mutu Pendidikan. Yogyakarta: Irchisod.

Maksudin, 2010, Pendidikan Nilai dan Karakter, Yogyakarta: UIN Sunan Kalijaga Press.

Mohrman, Susan Albers, et.al. 1994. School Based Management: Organizing for High Performance. San Francisco: JosseyBass.

Sutopo, H. B. 2001. Metodologi Penelitian Kualitatif. Surakarta: UNS Press.

Sutomo, 2015, Memuter 3 G OTA Berbasis Kearifan Lokal, Makalah.

Syafaruddin, 2002. Manajemen Mutu Terpadu dalam Pendidikan. Jakarta: PT. Raja Grasindo.

Undang-Undang Nomor 20 Tahun 2003. Sistem Pendidikan Nasional dan Penjelasannya. Yogyakarta: Media Wacana.

https://www.google.co.id/?gws_rd=cr,ssl\&ei= kKE6V9LyLMnsvgTYpbK4Bw\#q=pen gertian+prestasi. diunduk 18 Mei 2019 pukul 11.50 WIB

http://www.blogerch.com/2007/04/totalquality-management-tqm-ringkasan.html. diunduh 26 April 2019 